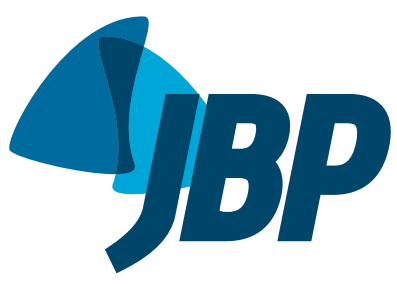

1. Departamento de Medicina, Faculdade de Medicina, Universidade de São Paulo, São Paulo (SP) Brasil.

Submitted: 30 June 2016. Accepted: 31 October 2016.

Study carried out in the Departamento de Medicina, Faculdade de Medicina, Universidade de São Paulo, São Paulo (SP) Brasil.

\title{
A murine model of elastase- and cigarette smoke-induced emphysema
}

\author{
Rubia Rodrigues ${ }^{1}$, Clarice Rosa Olivo', Juliana Dias Lourenço', Alyne Riane', \\ Daniela Aparecida de Brito Cervilha', Juliana Tiyaki Ito', \\ Milton de Arruda Martins' ${ }^{1}$, Fernanda Degobbi Tenório Quirino dos Santos Lopes ${ }^{1}$
}

\begin{abstract}
Objective: To describe a murine model of emphysema induced by a combination of exposure to cigarette smoke (CS) and instillation of porcine pancreatic elastase (PPE). Methods: A total of 38 C57BL/6 mice were randomly divided into four groups: control (one intranasal instillation of $0.9 \%$ saline solution); PPE (two intranasal instillations of PPE); CS (CS exposure for 60 days); and CS + PPE (two intranasal instillations of PPE $+\mathrm{CS}$ exposure for 60 days). At the end of the experimental protocol, all animals were anesthetized and tracheostomized for calculation of respiratory mechanics parameters. Subsequently, all animals were euthanized and their lungs were removed for measurement of the mean linear intercept $(\mathrm{Lm})$ and determination of the numbers of cells that were immunoreactive to macrophage (MAC)-2 antigen, matrix metalloproteinase (MMP)-12, and glycosylated $91-\mathrm{kDa}$ glycoprotein (gp91phox) in the distal lung parenchyma and peribronchial region. Results: Although there were no differences among the four groups regarding the respiratory mechanics parameters assessed, there was an increase in the $\mathrm{Lm}$ in the CS + PPE group. The numbers of MAC-2-positive cells in the peribronchial region and distal lung parenchyma were higher in the CS + PPE group than in the other groups, as were the numbers of cells that were positive for MMP-12 and gp91phox, although only in the distal lung parenchyma. Conclusions: Our model of emphysema induced by a combination of PPE instillation and CS exposure results in a significant degree of parenchymal destruction in a shorter time frame than that employed in other models of CS-induced emphysema, reinforcing the importance of protease-antiprotease imbalance and oxidant-antioxidant imbalance in the pathogenesis of emphysema.
\end{abstract}

Keywords: Tobacco; Models, animal; Emphysema; Respiratory physiological phenomena; Lung injury.

\section{INTRODUCTION}

Animal models of emphysema have been extensively used in order to provide a better understanding of the pathogenesis of the disease. This is due to the fact that studies involving human participants focus exclusively on morphological and molecular analysis of lung tissue fragments from patients undergoing surgical procedures or are in vitro studies conducted at a single time point.

The cigarette smoke (CS) and elastase models of emphysema are the most commonly used murine models of the disease, and both can produce pathological changes resembling human emphysema. However, given that neither can closely mimic the disease in humans, it is important to understand the advantages and disadvantages of each. (1) Although CS-induced emphysema models appear to best represent the pathogenesis of human emphysema, one major limitation of such models is that, regardless of how long animals are exposed to CS, the resulting alveolar enlargement is mild in comparison with that resulting from animal models of elastase-induced emphysema. ${ }^{(1-3)}$ Depending on the dose, intratracheal or intranasal instillation of elastase can induce severe emphysema in a short time, ${ }^{(1,4-7)}$ as well as a significant increase in alveolar enlargement, collagen fibers, and elastic fibers, suggesting a process of lung parenchymal remodeling. ${ }^{(4,6)}$ However, the main disadvantage of elastase models of emphysema is that they do not trigger all of the physiological events that CS models do, their relevance for therapeutic approaches therefore being limited. ${ }^{(1}$

Animal models of CS- and elastase-induced emphysema have been used not only to elucidate the structural changes in lung tissue but also to clarify the mechanistic insights involved in emphysema development. Although the protease-antiprotease imbalance hypothesis remains the most widely accepted hypothesis to explain the parenchymal destruction of emphysema, ${ }^{(8-11)}$ oxidative stress should also be taken into account, given that the oxidant burden is increased in smokers as a response to CS compounds. ${ }^{(12,13)}$ In an attempt to reduce the smoke exposure time required to induce emphysema and mimic as closely as possible the pathological features of human

Correspondence to:

Fernanda Lopes. Departamento de Medicina, Faculdade de Medicina, Universidade de São Paulo, Avenida Dr. Arnaldo, 455, Sala 1210, CEP 01246-903, São Paulo, SP, Brasil.

Tel.: 5511 3061-7180. Fax: 5511 3094-2621. E-mail: fernanda@experimental.fm.usp.br

Financial support: This study received financial support from the Fundação de Amparo à Pesquisa do Estado de São Paulo (FAPESP, São Paulo Research Foundation) and the Instituto dos Laboratórios de Investigação Médica do Hospital das Clínicas da Faculdade de Medicina da Universidade de São Paulo (LIMs-HC/FMUSP, University of São Paulo School of Medicine Hospital das Clínicas Laboratories for Medical Research). 
emphysema, we developed an experimental model of emphysema induced by a combination of instillation of porcine pancreatic elastase (PPE) and exposure to CS for 2 months only.

\section{METHODS}

The present study was approved by the Human and Animal Research Ethics Committee of the University of São Paulo School of Medicine, located in the city of São Paulo, Brazil. Six- to eight-week-old male C57BL/6 mice (weighing 20-25 g) were used in the study. All animals received humane care in compliance with the US National Institutes of Health Guide for the Care and Use of Laboratory Animals (NIH Publication no. 85-23, revised in 1996).

For emphysema induction, the animals were anesthetized with a combination of xylazine and ketamine (i.m., $5 \mathrm{mg} / \mathrm{kg}$ and $40 \mathrm{mg} / \mathrm{kg}$, respectively) and then challenged with an intranasal instillation of $50 \mu \mathrm{L}$ of type I PPE (E1250; Sigma-Aldrich, St. Louis, MO, USA) at a lower dose (i.e., $0.33 \mathrm{IU}$ ) than that used in other models of PPE-induced emphysema, given that our goal was to induce emphysema by combining instillation of PPE and exposure to CS. ${ }^{(14)}$ The animals received a total of two doses of PPE (one dose at day 0 and one dose at day 30). Control animals received $50 \mu \mathrm{L}$ of $0.9 \%$ saline solution (vehicle).

For animals undergoing CS exposure, the protocol began on day 1 . The animals were exposed to CS in a 28-L inhalation chamber with two inlets (one for air and one for smoke), one outlet, and a fan for better mixing of air and smoke inside the chamber. One of the inlets was set to deliver synthetic air flow at $2 \mathrm{~L} /$ min, and the other was set to deliver synthetic air flow coming from a Venturi system connected to a lit cigarette, suctioning the CS into the chamber. It was possible to change that flow rate to increase or decrease the amount of smoke in the chamber. After several measurements of the concentration of $\mathrm{CO}$ in the chamber, the flow rate was set to $1.5 \mathrm{~L} / \mathrm{min}$, which produced $\mathrm{CO}$ levels ranging from $250 \mathrm{ppm}$ to 350 ppm. Carboxyhemoglobin levels were maintained at $10 \pm 1.3 \%$ in all mice undergoing CS exposure. The animals were exposed to smoke from $12 \pm 1$ commercial filter cigarettes (each containing $0.8 \mathrm{mg}$ of nicotine, $10 \mathrm{mg}$ of tar, and $10 \mathrm{mg}$ of $\mathrm{CO}$ ), at a total particulate matter concentration of $411.4 \pm 30 \mu \mathrm{g} /$ $\mathrm{m}^{3}$ per day. Exposure duration was $60 \mathrm{~min}$ per day (i.e., two 30-min exposure periods) 5 days a week for 2 months. Control mice were exposed to room air. ${ }^{(15)}$

A total of 38 C57BL/ 6 mice were randomly divided into four groups (Figure 1 ):

1. control ( $n=9$ ), comprising mice receiving an intranasal instillation of $0.9 \%$ saline solution on day 0 and euthanized on day 60

2. PPE ( $n=9)$, comprising mice receiving two intranasal instillations of PPE (one on day 0 and one on day 30) and euthanized on day 60
3. CS ( $n=10)$, comprising mice exposed to CS twice a day 5 days a week for 60 days and euthanized on day 60

4. $C S+\operatorname{PPE}(n=10)$, comprising mice receiving two intranasal instillations of PPE (one on day 0 and one on day 30), undergoing the aforementioned CS exposure protocol from day 1 onward, and euthanized on day 60

At the end of the experimental protocol, all animals were deeply anesthetized with an intraperitoneal injection of thiopental $(70 \mathrm{mg} / \mathrm{kg})$, tracheostomized, and then connected to a ventilator for small animals (flexiVent $^{\mathrm{TM}}$; SCIREQ, Montreal, QC, Canada), the ventilator being set to a tidal volume of $10 \mathrm{~mL} / \mathrm{kg}$ and an RR of 120 breaths/min. All animals received an intraperitoneal injection of pancuronium bromide $(0.2 \mathrm{mg} / \mathrm{kg})$ in order to avoid increased work of breathing. ${ }^{(15)}$ Respiratory system input impedance was measured by the forced oscillation technique, a 16-s perturbation (at frequencies of $0.25-9.125 \mathrm{~Hz}$ ) being applied and the exhalation valve being kept closed.(16) Pressure was generated, and impedance was calculated as a function of the different frequencies. In order to calculate respiratory mechanics parameters such as airway resistance, tissue damping, and tissue elastance, we used a constant phase model described elsewhere. ${ }^{(17)}$

After calculation of the aforementioned parameters, a $2-\mathrm{cm}$ incision was made in the abdomen and the animals were euthanized by exsanguination from the abdominal aorta. Subsequently, the anterior chest wall was opened and the lungs were removed en bloc and fixed in $4 \%$ formaldehyde at a constant pressure of $20 \mathrm{cmH}_{2} \mathrm{O}$ for $24 \mathrm{~h}$, conventional histology being subsequently performed. In brief, lower- and upper-lobe specimens were embedded in paraffin and cut into $5-\mu \mathrm{m}$ sections that were stained with hematoxylin and eosin in order to measure the mean linear intercept (Lm), which is an indicator of mean alveolar diameter. ${ }^{(18)}$

The lung tissue was immunostained with the following antibodies: rat anti-mouse macrophage (MAC)-2 monoclonal antibody $\left(1: 50,000\right.$; CEDARLANE ${ }^{\circledR}$, Burlington, ON, Canada); polyclonal goat anti-mouse matrix metalloproteinase (MMP)-12 (1:500; Santa Cruz Biotechnology, Inc., Santa Cruz, CA, USA); and polyclonal goat anti-mouse glycosylated 91-kDa glycoprotein (gp91phox; 1:300; Santa Cruz Biotechnology, Inc.).

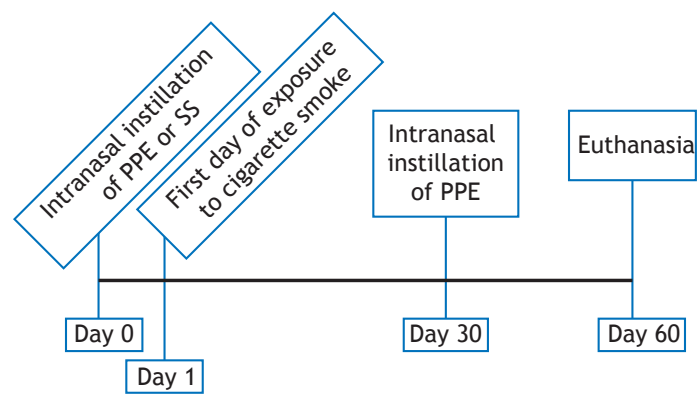

Figure 1. Timeline of the experimental protocol. PPE: porcine pancreatic elastase; and SS: saline solution. 
A biotin-streptavidin-peroxidase method was used. Secondary antibodies included anti-rabbit VECTASTAIN ${ }^{\circledR}$ ABC kit, anti-goat VECTASTAIN ${ }^{\circledR}$ ABC kit, and anti-rat VECTASTAIN ${ }^{\circledR} A B C$ kit (Vector Laboratories, Inc., Burlingame, CA, USA), which were also used without a primary antibody, serving as a negative control.(19)

For histomorphometry, a 100-point ocular grid of known area was placed in the microscope eyepiece. ${ }^{(20)}$ For each animal, 20 randomly selected nonoverlapping fields of lung parenchyma were examined under light microscopy (magnification, $\times 200$ ). The Lm was measured by counting how many times the grid lines intercepted the alveolar walls, being calculated by the following equation:

$$
L m=\text { Ltotal/NI }
$$

where Ltotal is the sum of all grid segments, calculated by measuring each segment with a ruler (Carl Zeiss Microscopy $\mathrm{GmbH}$, Jena, Germany) under the microscope, and $N I$ is the average number of times that the lines intersected the alveolar walls. All Lm values were expressed in micrometers $(\mu \mathrm{m})$.

Histomorphometry was also used in order to determine the numbers of cells that were immunoreactive to MAC-2, MMP-12, and gp91phox in the distal lung parenchyma and peribronchial region by a point-counting technique with the aforementioned grid placed in the microscope eyepiece (magnification, $\times 400$ ). For each animal, 15 fields of lung parenchyma and 5 airways were randomly selected. The results were expressed in cells $/ \mu \mathrm{m}^{2}$. $\left.21-24\right)$

Statistical analysis was performed with the program SigmaStat, version 11 (Systat Software, Inc., San Jose, CA, USA). The four groups of mice were compared by one-way ANOVA. Differences were considered significant at $p<0.05$.

\section{RESULTS}

On day 60 of the experimental protocol, no significant differences were found among the four groups of mice regarding the respiratory mechanics parameters assessed (i.e., airway resistance, tissue damping, and tissue elastance; Figure 2). The Lm was found to be higher in the CS + PPE group than in the other groups ( $p<0.05$; Figure 3 ), an increased Lm being a hallmark of pulmonary emphysema.

Figure 4 shows the numbers of cells that were positive for MAC-2 in the peribronchial region and distal lung parenchyma. An increased number of macrophages in the peribronchial region $(p<0.05)$ and distal lung parenchyma ( $p<0.005)$ were found in the CS + PPE group.

There were no significant differences among the four groups regarding the number of cells that were positive for MMP-12 in the peribronchial region (Figure 5A). However, in the distal lung parenchyma, the number of cells that were positive for MMP-12 was higher in the CS + PPE group than in the control group ( $p=$ 0.007; Figure 5B).
The number of cells that were positive for gp91phox in the peribronchial region was higher in the CS group than in the control and PPE groups ( $p=0.001$; Figure $6 \mathrm{~A})$. In the distal lung parenchyma, the number of cells that were positive for gp91phox was higher in the CS group than in the control group ( $p=0.03$ ), as well as being higher in the CS + PPE group than in the control and PPE groups ( $p<0.003$; Figure 6B).

\section{DISCUSSION}

In the present study, we tested an experimental model of emphysema induced by a combination of short-term exposure to CS and instillation of PPE. After 2 months, there was an increase in the Lm, as well as macrophage infiltration in the peribronchial region and distal lung parenchyma, together with an increase in the numbers of cells that were positive for MMP-12 and gp91phox in the distal lung parenchyma.

The fact that no functional changes were found in the present study is probably due to the fact that there
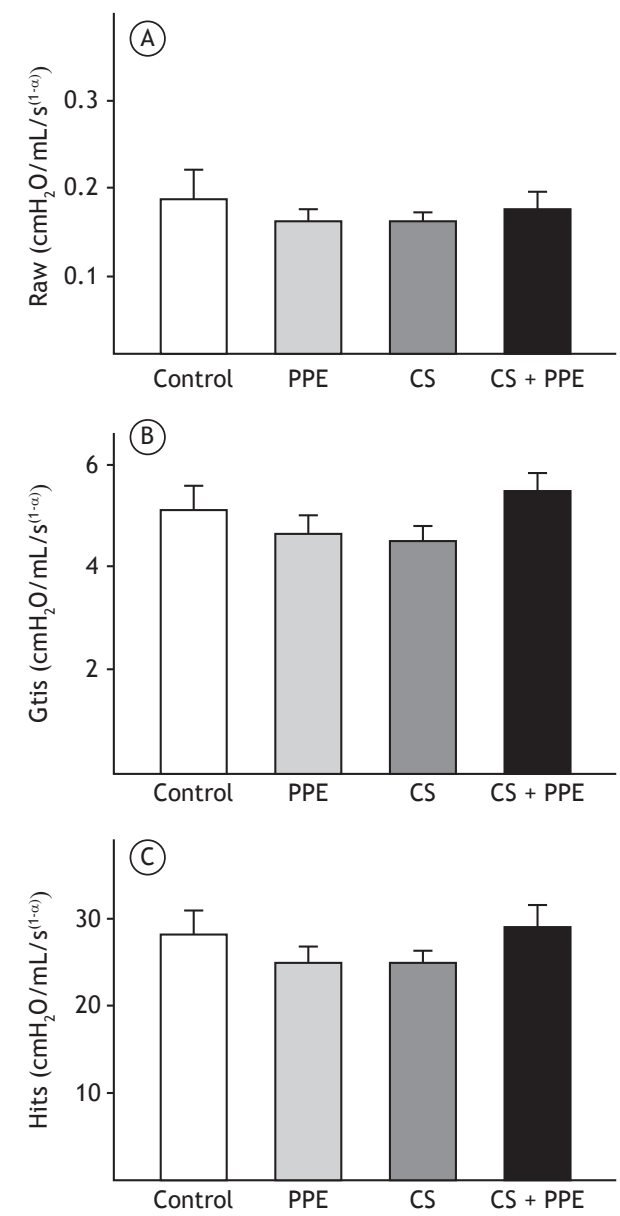

Figure 2. Respiratory mechanics parameters in the four experimental groups, expressed as mean $\pm S E$. In $A$, airway resistance (Raw); in B, tissue damping (Gtis); and in $\mathrm{C}$, tissue elastance (Hits). There were no significant differences in any of the parameters assessed among the experimental groups. PPE: porcine pancreatic elastase; and CS: cigarette smoke. 


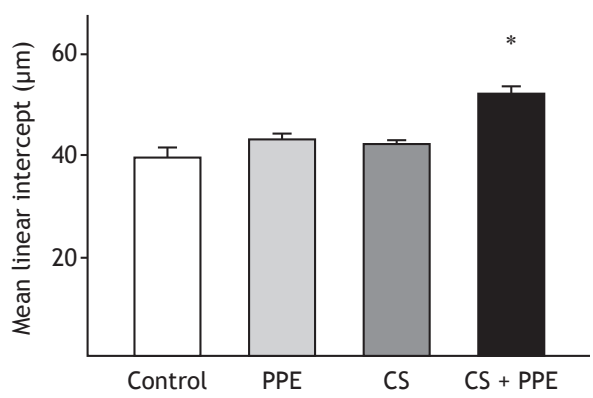

Figure 3. Mean linear intercept ( $\mathrm{Lm}$ ) values measured in the four experimental groups, expressed as mean \pm SE. The CS + PPE group showed an increase in Lm values in comparison with the other groups. PPE: porcine pancreatic elastase; and CS: cigarette smoke. $* p<0.05$ vs. control, PPE, and CS groups.

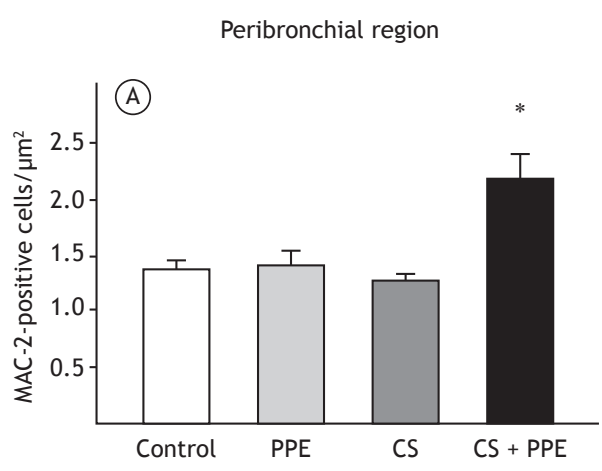

Distal lung parenchyma

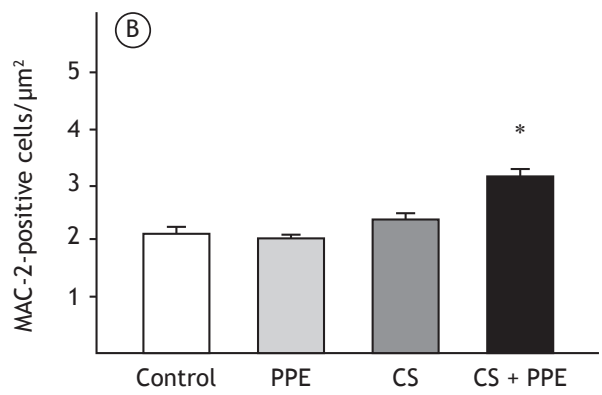

Figure 4. Number of positive cells for macrophage (MAC)-2 in the four experimental groups, expressed as mean \pm SE. There was an increase in the number of positive cells for MAC-2 in the peribronchial region (in $A ; * p<0.05$ ) and distal lung parenchyma (in $B ;{ }^{*} p<0.005$ ) in the CS + PPE group in comparison with the other groups. PPE: porcine pancreatic elastase; and CS: cigarette smoke.

was less alveolar enlargement in our study than in studies involving models of PPE-induced emphysema and higher doses of elastase ${ }^{(25)}$ or in studies involving models of CS-induced emphysema and longer exposure times. ${ }^{(15)}$ In addition, some studies have shown that assessment of respiratory mechanics does not reflect the presence of emphysema as well as does morphometric analysis. ${ }^{(21,26)}$ Foronjy et al. ${ }^{(27)}$ found no changes in lung compliance despite the presence of
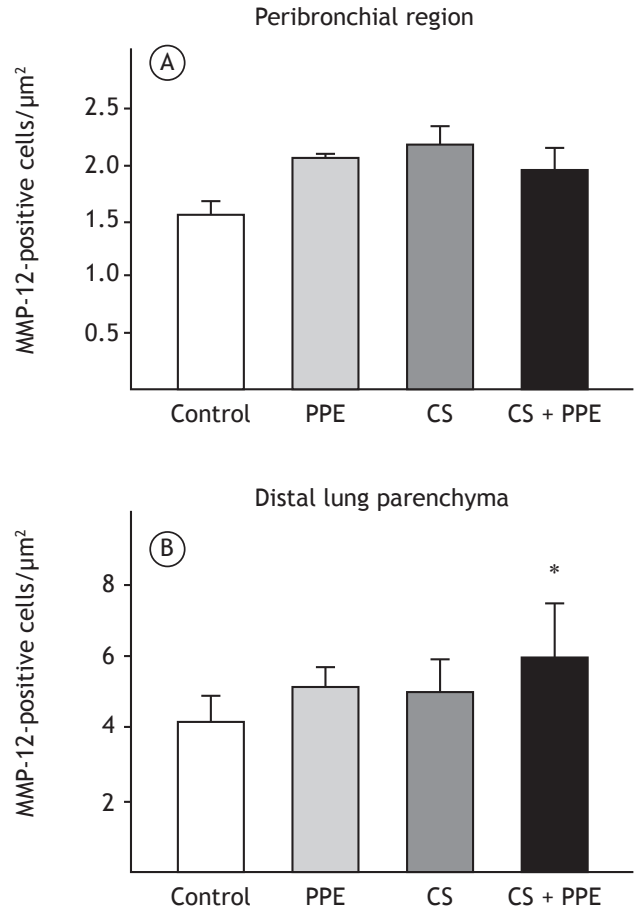

Figure 5. Number of positive cells for matrix metalloproteinase (MMP)-12 in the four experimental groups, expressed as mean \pm SE. There were no differences among the experimental groups regarding the number of MMP-12-positive cells in the peribronchial region (in $A$ ). The number of positive cells for MMP-12 in the distal lung parenchyma was higher in the CS + PPE group than in the control group (in $B ;{ }^{*} p=0.007$ ). PPE: porcine pancreatic elastase; and CS: cigarette smoke.

significant emphysema, with no correlation between emphysema as measured by morphometric analysis and lung compliance. They concluded that this lack of correlation occurs because the mechanisms involved in anatomic emphysema might be distinct from those that cause the loss of elastic recoil. ${ }^{(27)}$

An imbalance between protease and antiprotease activity in the lung remains the most widely accepted mechanism for parenchymal destruction in emphysema. ${ }^{(10,14,28-30)}$ In addition, studies have shown that MMPs, particularly MMP-12, play an important role in attacking the protein components of the lung parenchymal extracellular matrix. ${ }^{(31,32)}$

MMP-12 is mainly produced by alveolar macrophages $^{(33)}$ and is recognized to play an important role in emphysema. One group of authors exposed MMP-12 knockout mice to CS 6 days a week for 6 months and observed no increase in macrophage number or parenchymal destruction. ${ }^{(34)}$ In addition, there have been reports of increased MMP-12 expression in macrophages in smokers and greater MMP-12 activity in the sputum of patients with COPD than in that of smokers without airflow limitation. $(35,36)$

In the present study, there was an increase in macrophages in the peribronchial region and distal lung parenchyma, as well as an increase in the number of cells that were positive for MMP-12 in comparison 

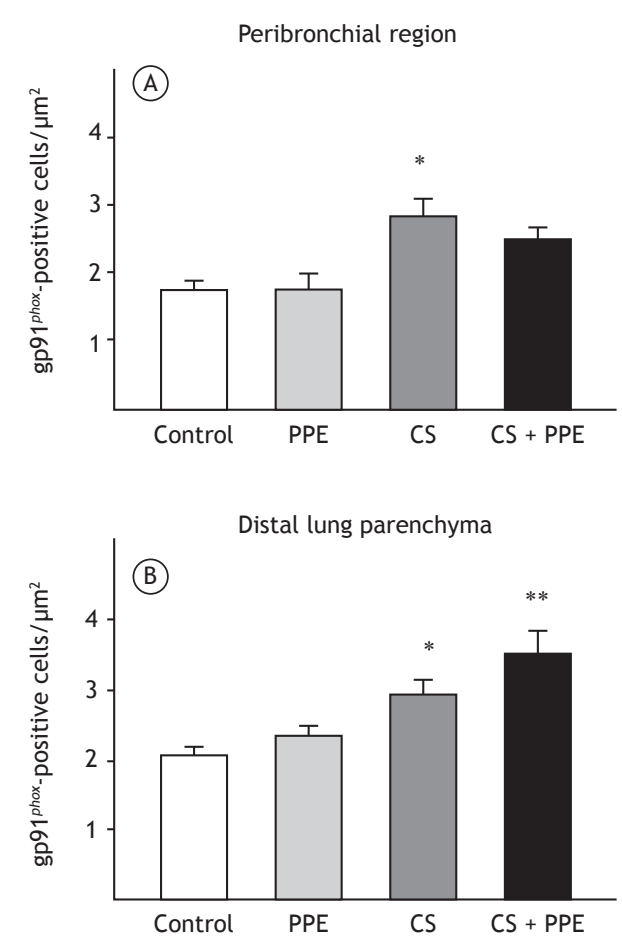

Figure 6. Number of positive cells for glycosylated $91-k D a$ glycoprotein (gp91phox) in the four experimental groups, expressed as mean $\pm \mathrm{SE}$. The number of gp91phox-positive cells in the peribronchial region was higher in the CS group than in the control and PPE groups (in $A ; * p=0.001$ ). In the distal lung parenchyma, the number of gp91phox-positive cells was higher in the CS group than in the control group (in $B ; * p=0.03$ ), as well as being higher in the CS + PPE group than in the control and PPE groups (in $\mathrm{B} ; * * \mathrm{p}<0.003$ ). PPE: porcine pancreatic elastase; and CS: cigarette smoke.

with the control group, although only in the distal lung parenchyma. Although MMP-12 levels were higher in the PPE and CS groups than in the control group, the difference was not significant. These findings are consistent with the structural changes observed in the distal lung parenchyma.

In the present study, the Lm was found to be higher in the CS + PPE group than in the other groups. A similar increase in the Lm has previously been observed, although only after 6 months of CS exposure ${ }^{(15)}$ or with the use of twice as much PPE as was used in the present study. ${ }^{(25,37)}$

In the present study, oxidative stress was measured by determining the number of positive cells for gp91phox, which is the heme-binding subunit of the superoxide-generating NADPH oxidase. ${ }^{(38)}$ CS contains many oxidants and reactive oxygen species promoting an environmental oxidant burden, which is augmented by additional release of oxidants from inflammatory cells, culminating in body tissue destruction. $(39,40)$ Alveolar macrophages release more reactive oxygen species in smokers than in nonsmokers, plasma antioxidant capacity being reduced in the former. ${ }^{(39)}$ In the present study, exposure to CS was found to result in an increase in gp91phox-positive cells in the peribronchial region and distal lung parenchyma. The number of gp91phox-positive cells in the peribronchial region was higher in the CS group than in the control and PPE groups. In addition, there was an increase in gp91phox-positive cells in the distal lung parenchyma in the CS and CS + PPE groups. This increase was enhanced by a combination of CS exposure and PPE instillation, the presence of alveolar enlargement suggesting that oxidants play an important role in our murine model of emphysema.

Although oxidative stress has been described as an important mechanism in the development of emphysema, ${ }^{(41-43)} \mathrm{NADPH}$ oxidase has been shown to play an important role in restraining MMP activity in macrophages, MMP-12 activity in vitro having been shown to be greater in oxidant-deficient macrophages than in gp91phox-null and wild-type macrophages. ${ }^{(44)}$ In addition, spontaneous, progressive emphysema similar to that observed in wild-type animals exposed to CS has been shown to develop in vivo in gp91phox knockout mice. ${ }^{(44)}$ The differences between our results and those of the aforementioned study ${ }^{(44)}$ might be due to differences in experimental protocols between the two studies.

Our model of emphysema induced by a combination of CS exposure and PPE instillation results in a significant degree of parenchymal destruction in a shorter time frame than that employed in previous studies, reinforcing the importance of protease-antiprotease imbalance and oxidant-antioxidant imbalance in the pathogenesis of emphysema. Given the diversity of experimental models in the literature, it is important to choose carefully the best model for each purpose. A murine model of emphysema induced by a combination of CS exposure and PPE instillation might be useful for evaluating structural changes occurring during the processes of parenchymal destruction and remodeling in emphysema.

\section{REFERENCES}

1. Wright JL, Cosio M, Churg A. Animal models of chronic obstructive pulmonary disease. Am J Physiol Lung Cell Mol Physiol. 2008;295(1):L1-15. https://doi.org/10.1152/ajplung.90200.2008

2. Lopes FD, Toledo AC, Olivo CR, Prado CM, Leick EA, Medeiros MC, et al. A comparative study of extracellular matrix remodeling in two murine models of emphysema. Histol Histopathol. 2013;28(2):26976

3. Mahadeva R, Shapiro SD. Chronic obstructive pulmonary disease * 3: Experimental animal models of pulmonary emphysema. Thorax 2002;57(10):908-14. https://doi.org/10.1136/thorax.57.10.908

4. Janoff A, White R, Carp H, Harel S, Dearing R, Lee D. Lung injury induced by leukocytic proteases. Am J Pathol. 1979;97(1):111-36.

5. Lieberman J. Elastase, collagenase, emphysema, and alpha1antitrypsin deficiency. Chest. 1976;70(1):62-7. https://doi. org/10.1378/chest.70.1.62

6. Janoff A. Elastases and emphysema. Current assessment of the protease-antiprotease hypothesis. Am Rev Respir Dis. 1985; 132(2):417-33.

7. Lesser M, Padilla ML, Cardozo C. Induction of emphysema in hamsters by intratracheal instillation of cathepsin B. Am Rev Respir 
Dis. 1992;145(3):661-8. https://doi.org/10.1164/ajrccm/145.3.661

8. Churg A, Cosio M, Wright JL. Mechanisms of cigarette smokeinduced COPD: insights from animal models. Am J Physiol Lung Cell Mol Physiol. 2008;294(4):L612-31. https://doi.org/10.1152/ ajplung.00390.2007

9. Parks WC, Shapiro SD. Matrix metalloproteinases in lung biology. Respir Res. 2001;2(1):10-9.

10. Barnes PJ, Shapiro SD, Pauwels RA. Chronic obstructive pulmonary disease: molecular and cellular mechanisms. Eur Respir J 2003;22(4):672-88. https://doi.org/10.1183/09031936.03.00040703

11. Shapiro SD. Proteinases in chronic obstructive pulmonary disease. Biochem Soc Trans. 2002;30(2):98-102. https://doi.org/10.1042/ bst0300098

12. Rahman I. Pharmacological antioxidant strategies as therapeutic interventions for COPD. Biochim Biophys Acta. 2012;1822(5):714 28. https://doi.org/10.1016/j.bbadis.2011.11.004

13. Vlahos R, Bozinovski $S$. Recent advances in pre-clinical mouse models of COPD. Clin Sci (Lond). 2014;126(4):253-65. https://doi. org/10.1042/CS20130182

14. Ito $S$, Ingenito EP, Brewer KK, Black LD, Parameswaran $H$, Lutchen $\mathrm{KR}$, et al. Mechanics, nonlinearity, and failure strength of lung tissue in a mouse model of emphysema: possible role of collagen remodeling. J Appl Physiol (1985). 2005:98(2):503-11. https://doi. org/10.1152/japplphysiol.00590.2004

15. Toledo AC, Magalhaes RM, Hizume DC, Vieira RP, Biselli PJ, Moriya $\mathrm{HT}$, et al. Aerobic exercise attenuates pulmonary injury induced by exposure to cigarette smoke. Eur Respir J. 2012;39(2):254-64 https://doi.org/10.1183/09031936.00003411

16. Gomes RF, Shen X, Ramchandani R, Tepper RS, Bates JH Comparative respiratory system mechanics in rodents. J Appl Physio (1985). 2000;89(3):908-16.

17. Hantos Z, Daróczy B, Suki B, Nagy S, Fredberg JJ. Input impedance and peripheral inhomogeneity of dog lungs. J Appl Physiol (1985) 1992;72(1):168-78.

18. Margraf LR, Tomashefski JF Jr., Bruce MC, Dahms BB. Morphometric analysis of the lung in bronchopulmonary dysplasia. Am Rev Respir Dis. 1991;143(2):391-400. https://doi.org/10.1164/ajrccm/143.2.391

19. Standiford TJ, Kunkel SL, Greenberger MJ, Laichalk LL, Strieter RM. Expression and regulation of chemokines in bacterial pneumonia. $J$ Leukoc Biol. 1996;59(1):24-8. https://doi.org/10.1159/000109191

20. Weibel ER. Principles and methods for the morphometric study of the lung and other organs. Lab Invest. 1963;12:131-55

21. Anciaes AM, Olivo CR, Prado $\mathrm{CM}$, Kagohara $\mathrm{KH}$, Pinto Tda $\mathrm{S}$, Moriya HT, et al. Respiratory mechanics do not always mirror pulmonary histological changes in emphysema. Clinics (Sao Paulo) 2011;66(10):1797-803.

22. van der Poll T, Opal SM. Pathogenesis, treatment, and prevention of pneumococcal pneumonia. Lancet. 2009;374(9700):1543-56. https:// doi.org/10.1016/S0140-6736(09)61114-4

23. Radak Z, Chung HY, Goto S. Systemic adaptation to oxidative challenge induced by regular exercise. Free Radic Biol Med. 2008:44(2):153-9 https://doi.org/10.1016/j.freeradbiomed.2007.01.029

24. Reis Gonçalves CT, Reis Gonçalves CG, de Almeida FM, Lopes FD, dos Santos Durão AC, dos Santos FA, et al. Protective effects of aerobic exercise on acute lung injury induced by LPS in mice. Crit Care. 2012;16(5):R199. https://doi.org/10.1186/cc11807

25. Robertoni FS, Olivo CR, Lourenço JD, Gonçalves NG, Velosa AP Lin CJ, et al. Collagenase mRNA Overexpression and Decreased Extracellular Matrix Components Are Early Events in the Pathogenesis of Emphysema. PLoS One. 2015;10(6):e0129590. https://doi.org/10.1371/journal.pone.0129590

26. Guerassimov A, Hoshino Y, Takubo Y, Turcotte A, Yamamoto M, Ghezzo H, et al. The development of emphysema in cigarette smokeexposed mice is strain dependent. Am J Respir Crit Care Med. 2004;170(9):974-80. https://doi.org/10.1164/rccm.200309-12700C

27. Foronjy RF, Mercer BA, Maxfield MW, Powell CA, D'Armiento
J, Okada Y. Structural emphysema does not correlate with lung compliance: lessons from the mouse smoking model. Exp Lung Res. 2005;31(6):547-62. https://doi.org/10.1080/019021490951522

28. Snider GL, Lucey EC, Stone PJ. Animal models of emphysema. Am Rev Respir Dis. 1986;133(1):149-69. https://doi.org/10.1164/ arrd.1986.133.1.149

29. Stockley RA. Proteases and antiproteases. Novartis Found Symp. 2001;234:189-99; discussion 199-204. https://doi. org/10.1002/0470868678.ch12

30. Takubo Y, Guerassimov A, Ghezzo H, Triantafillopoulos A, Bates $\mathrm{JH}$, Hoidal JR, et al. Alpha1-antitrypsin determines the pattern of emphysema and function in tobacco smoke-exposed mice: parallels with human disease. Am J Respir Crit Care Med. 2002;166(12 Pt 1):1596-603. https://doi.org/10.1164/rccm.2202001

31. Churg A, Zhou S, Wright JL. Series "matrix metalloproteinases in lung health and disease": Matrix metalloproteinases in COPD. Eur Respir J. 2012;39(1):197-209. https://doi.org/10.1183/09031936.00121611

32. Shapiro SD. Elastolytic metalloproteinases produced by human mononuclear phagocytes. Potential roles in destructive lung disease. Am J Respir Crit Care Med. 1994:150(6 Pt 2):S160-4. https://doi. org/10.1164/ajrccm/150.6_Pt_2.S160

33. Shipley JM, Wesselschmidt RL, Kobayashi DK, Ley TJ, Shapiro SD. Metalloelastase is required for macrophage-mediated proteolysis and matrix invasion in mice. Proc Natl Acad Sci U S A. 1996;93(9):3942-6. https://doi.org/10.1073/pnas.93.9.3942

34. Hautamaki RD, Kobayashi DK, Senior RM, Shapiro SD. Requirement for macrophage elastase for cigarette smoke-induced emphysema in mice. Science. 1997;277(5334):2002-4. https://doi.org/10.1126/ science. 277.5334 .2002

35. Demedts IK, Morel-Montero A, Lebecque S, Pacheco Y, Cataldo D Joos GF, et al. Elevated MMP-12 protein levels in induced sputum from patients with COPD. Thorax. 2006:61(3):196-201. https://doi. org/10.1136/thx.2005.042432

36. Woodruff PG, Koth LL, Yang YH, Rodriguez MW, Favoreto $S$ Dolganov GM, et al. A distinctive alveolar macrophage activation state induced by cigarette smoking. Am J Respir Crit Care Med. 2005;172(11):1383-92. https://doi.org/10.1164/rccm.200505-6860C

37. Lourenço JD, Neves LP, Olivo CR, Duran A, Almeida FM, Arantes $\mathrm{PM}$, et al. A treatment with a protease inhibitor recombinant from the cattle tick (Rhipicephalus Boophilus microplus) ameliorates emphysema in mice. PLoS One. 2014;9(6):e98216. https://doi. org/10.1371/journal.pone.0098216

38. Yu L, Quinn MT, Cross AR, Dinauer MC. Gp91(phox) is the heme binding subunit of the superoxide-generating NADPH oxidase. Proc Natl Acad Sci U S A. 1998;95(14):7993-8. https://doi.org/10.1073/ pnas.95.14.7993

39. Domej W, Oettl K, Renner W. Oxidative stress and free radicals in COPD-implications and relevance for treatment. Int J Chron Obstruct Pulmon Dis. 2014;9:1207-24. https://doi.org/10.2147/COPD.S51226

40. MacNee W. Oxidants and COPD. Curr Drug Targets Inflamm Allergy. 2005;4(6):627-41. https://doi.org/10.2174/156801005774912815

41. de Moura RS, Pires KM, Santos Ferreira T, Lopes AA, Nesi RT, Resende AC, et al. Addition of açaí (Euterpe oleracea) to cigarettes has a protective effect against emphysema in mice. Food Chem Toxicol. 2011;49(4):855-63. https://doi.org/10.1016/j.fct.2010.12.007

42. Valenca SS, Castro P, Pimenta WA, Lanzetti M, Silva SV, BariaFidalgo $\mathrm{C}$, et al. Light cigarette smoke-induced emphysema and NFkappaB activation in mouse lung. Int J Exp Pathol. 2006;87(5):37381. https://doi.org/10.1111//.1365-2613.2006.00492.x

43. Valença SS, Rueff-Barroso CR, Pimenta WA, Melo AC, Nesi RT, Silva MA, et al. L-NAME and L-arginine differentially ameliorate cigarette smoke-induced emphysema in mice. Pulm Pharmacol Ther. 2011;24(5):587-94. https://doi.org/10.1016/j.pupt.2011.05.006

44. Kassim SY, Fu X, Liles WC, Shapiro SD, Parks WC, Heinecke JW $\mathrm{NADPH}$ oxidase restrains the matrix metalloproteinase activity of macrophages. J Biol Chem. 2005;280(34):30201-5. https://doi. org/10.1074/jbc.M503292200 